This item was submitted to Loughborough's Research Repository by the author.

Items in Figshare are protected by copyright, with all rights reserved, unless otherwise indicated.

\title{
Racisms and the experiences of minorities in amateur football in the UK and Europe
}

PLEASE CITE THE PUBLISHED VERSION

https://www.routledge.com//9780415697170

\section{PUBLISHER}

Routledge

VERSION

AM (Accepted Manuscript)

\section{PUBLISHER STATEMENT}

This work is made available according to the conditions of the Creative Commons Attribution-NonCommercialNoDerivatives 4.0 International (CC BY-NC-ND 4.0) licence. Full details of this licence are available at: https://creativecommons.org/licenses/by-nc-nd/4.0/

\section{LICENCE}

CC BY-NC-ND 4.0

\section{REPOSITORY RECORD}

Bradbury, Steven. 2019. "Racisms and the Experiences of Minorities in Amateur Football in the UK and Europe". figshare. https://hdl.handle.net/2134/24536. 


\section{Dr Steven Bradbury, Loughborough University, UK}

\section{Racisms and the experiences of minorities in amateur football in the UK and Europe}

\section{Introduction}

Over the last twenty years, there has been a steadily growing body of academic research which has focused on issues of racism in professional football in the UK and Europe. What distinguishes the approach developed in this chapter is its focus on the previously underresearched area of racism and minority experiences of amateur football. Around 21 million people are registered to take part in organised amateur football in the UK and Europe and a further 40 million people are estimated to play football recreationally without being registered at amateur clubs. To this end, amateur football can be understood to be a prominent leisure activity for a significant percentage of the populations of Europe, including large numbers drawn from minority backgrounds. This is important since as Carrington points out, football, in common with many other sports, 'remains a critical site for the reproduction and re-articulation of forms of racial knowledge and common-sense and is an important location in the contested struggles over ideology, politics and identity' (2010: 175). From this inherently sociological perspective, sporting practice does not take place in a social, cultural or political vacuum, but, rather, it is reflective of and reflects back upon a series of historically inscribed and deeply racialised power relations embedded within the societies in which it takes place. Further, the development, organisation and practice of sport can be understood as a distinctly racial formation within which a series of dominant social, economic and political forces have shaped the content and importance of racial meanings and categories. To this end, sport is both receptive to and productive of racial meanings, and through the lens of sport social relations between peoples have become structured by the signification of human biological and cultural characteristics in such a way as to define and construct differential social collectivities along distinctly racial, ethnic and cultural lines.

Sport is also a site in which old biological and new cultural racisms impinge upon and are generated by sporting practice and have become manifest in sporting arenas in explicit and more coded forms. Anthias and Yuval Davis have argued that racisms need to be recognised 
as a multiplicity of 'modes of exclusion, inferiorisation, subordination and exploitation that present specific and different characters in different social and historical contexts' (1993:2). Referring to racisms in the plural recognises the complexity and diversity of racisms and their often contradictory character and supports the assertion that 'there is no-one monolithic racism but numerous historical situated racisms' (Back et al 2001:9). Recognising the plurality of racisms provides a useful conceptual starting point from which to examine the myriad processes and outcomes of overt, culturally coded, and more institutional forms of racism and discrimination in sport. In particular, it allows for enhanced understanding of the different ways in which different minorities experience different forms of racisms in sport across a range of intersectional indices, including gender, social class, religious affiliation and national political contexts (Rowe et al 2000, Scraton et al 2005, Kay 2006, Ratna 2007, Hylton 2009).

This latter point is especially relevant given the steady increase and more recent acceleration of the ethnic, cultural and religious diversity within the national populations of many European countries. Since the 1950s and 1960s, non-European in-migration trajectories to Western Europe have been underscored by the settlement of populations drawn from former colonies and have more recently been strongly linked to the growth in asylum seekers and refugees fleeing political persecution and armed conflicts in the Middle East, Asia and Africa (Bloch and Levy 1999, Pillai et al 2006). Since the 1990s, the continent has also experienced significant population movements across national borders amongst cohorts drawn from European origin, following the incorporation of the Schengen agreement into European Union law in 1997 and the expansion of EU member states from the mid 2000s onward. Conversely, many post communist countries in Central and Eastern Europe appear relatively culturally homogeneous with few 'visible' ethnic minorities, although the presence of national and religious minorities arguably cuts across east-west regional divides and the political construction of nation state boundaries. Whilst it is of course the case that a range of structural, cultural and political factors have impacted differentially in shaping the parameters of societal inclusion and exclusion amongst different minority groups across a range of national contexts, it is likely too that minorities have some shared experiences of overt and culturally coded forms of racialised abuse and more institutionalised forms of racism and discrimination. 
In the context of this report, the term 'minority' is used as a broad descriptive marker to refer to ethnically, culturally, religiously and sub-nationally distinct populations resident within nation state boundaries. This broad conceptualisation of 'minorities' includes both $2^{\text {nd }}$ and $3^{\text {rd }}$ generational 'settled' minority communities and more recent economic migrants and asylum and refugee groups drawn from a range of European and non-European backgrounds who presently reside in countries in which they make up a numerical minority. This broad definition of 'minorities' is premised on the recognition that minority status is both objectively ascribed (by the dominant society) and subjectively applied (by minority groups) as a means marking out ethnic, cultural, religious and sub-national difference. Whilst these differences are often applied negatively as a basis for hostility and discrimination, they are also applied positively in terms of cultural identity, group solidarity and collective resistance to racisms. This is especially the case within the cultural arena of sports and with particular respect to professional and amateur football. This chapter will begin by illustrating the ways in which racisms have been 'played out' and conceptualised in the professional game before providing a full examination of the practices, experiences and contestation of racisms at the amateur level of the sport. In doing so, the chapter will draw primarily on recent empirical and ethnographic research studies conducted in the UK and Europe.

\section{Racisms in professional football}

Much of the academic examination of racisms in sport in the UK and Europe has focused on the elite echelons of professional football. Academic inquiry initially emerged in this area in the 1980s in the UK as a response to growing public concern regarding overt forms of individual and orchestrated racist abuse from supporters which utilised a series of demeaning epithets to describe and demean black players (Cashmore 1982, Williams 1984, 1992). More recently, a number of authors have referenced the uneven but residual permanence of overt racism targeting black players in countries such as England, Germany and the Netherlands and have also identified the continuation of crude forms of openly antiblack sentiment at matches in Southern, Central and Eastern Europe (Back et al 2001, Van Sterkenburg et al 2005, Kassimeris 2007, 2009a, 2009b, Llopis-Giog 2009, Bradbury et al 2011). 
Linkages between far right political parties and the activities of spectator formations have been well documented in academic research, especially with regard to support for the English national team where right wing ideologies have chimed most obviously with historically embedded ideas around 'race', nation, and cultural exclusivity (Williams, 1992, Garland and Rowe 2001; Back et al 2001). Research studies in Italy and Spain have also examined connections between Ultra fan networks, racisms and hooliganism (Roversi 1994, Spaaij and Vinas 2005). More recently, Kassimeris (2009a) has identified the rise of new forms of politically orientated racism, xenophobia and hyper-nationalism at lower league domestic football matches in post-unification Germany. Similarly, there have been noted attempts to re-assert a sense of ethno-centric (white) national identity in and through football in (re)emergent countries in Eastern Europe and the Balkans region. For example, the Ukrainian far right political party Svoboda has actively conjoined football, anti-immigrant sentiment and nationalist ideologies and has been involved in violent confrontation with the civil and football authorities (FARE 2010).

Over the last ten years, a number of authors have alluded to the multiplicity of ways in which racisms are manifest in football spectator culture from more obvious forms of individual and orchestrated abuse to patterns of cultural interchange and coded discourse that takes place across white spectator formations. These continued expressions of racisms are premised on shared racially structured antipathies and the celebration of homogenously white and racially closed birthplace localisms, and represent the defence of prized (white) cultural space against wider social (and multicultural) change (Back et al 1998, 2001, Robson 2000, Nash 2000). More subtle, nuanced, forms of racist expression of this kind are arguably underpinned by strongly embedded forms of cultural racisms which prioritise and heighten perceived differences between majority and minority populations across fissures of 'race', culture and religion. This is especially evident in the reported rise in openly expressed Islamophobic sentiment and targeted abuse of Muslim players at professional matches in the UK and Europe (Van Sterkenburg 2005, Burdsey 2011, Ahmed 2011).

In recent years, there has been an increased academic focus on examining patterns of institutional racism and discrimination in professional football in the UK and Europe. In 
particular, these studies have focused on the ways in which a series of racially closed institutional practices embedded within the dominant and largely unchallenged white hegemonic structures of professional football impact disproportionately on levels of representation of minorities across all tiers of the game. For example, in the UK a number of research studies have highlighted a series of relatively 'closed' operational approaches to youth talent identification at professional clubs which have historically failed to incorporate a range of sites and local settings in which young minority players are present (Bains and Patel 1996, Bains 2005, Football Task Force 1998, IFC 2003, CRE 2004). The work of Burdsey $(2004,2007)$ is especially instructive in illustrating the ways in which these practices are underpinned by a series of cultural misconceptions which portray South Asian cultures as static, falsely homogeneous and culturally disinterested in football. Similar processes of cultural stereotyping which have constructed young black players as 'difficult', 'bad tempered' and 'lacking in social etiquette' have been evidenced within professional club youth academies in Denmark and the Netherlands and (Agergaard and Sorenson 2009, Kassimeris 2009b ). Within these 'limited conditions of equality' young minority players are expected to exercise much greater adaptation to the social and cultural mores of dominant majority populations at clubs and to 'leave their cultural identity at the door'. These findings chime strongly with the work of King (2004a, 2004b) who asserts that the upwardly mobile career trajectories of minority players are premised on the successful negotiation of dialogic, non-verbal and ritualised processes through which the attainment of 'cultural passports' and contingent inclusions are granted or withheld within the normative white spaces that define the football workplace.

Bradbury et al (2011) has suggested that the under-representation of minority, especially, black, coaches in the professional game is underscored by the internalisation of a series of historically inscribed cultural stereotypes on the part of club owners which equate black coaches with 'physicality over intellect', 'uncertainty' and 'risk'. This research also alluded to tendencies of club owners to recruit coaches from a limited 'diversity pool' of already experienced (mostly white) applicants embedded within the social and cultural 'boys clubs' of professional football networks. Bradbury et al argues that these practices of racially inflected institutional closure are also evidenced in mechanisms of personal recommendation, sponsored mobility and patronage which underpin recruitment to senior 
administrative positions at professional clubs. Whilst these practices might be unconscious, unintentional and 'embodied', they nevertheless gravitate against minorities who are positioned outside of the dominant networks of mutual acquaintance of the football industry and favour individuals drawn from recognisable (white) backgrounds with similar cultural norms, values and behaviours.

\section{Overt and culturally coded racisms in amateur football}

Long et al (2009) have argued that the experiences of minorities of sport and leisure are mediated by racisms and that racist expression seems especially strong at the recreational level of organised men's amateur football. For example, Long et al's (2001) study of racism in amateur football in Northern England revealed clear differences in the perceptions and experiences of racism and the continued existence of racialised tensions between players from different ethnic backgrounds. The authors concluded that 'despite some confusion as to what constitutes racist behaviour, the research team were left in no doubt that it does occur and consequently stronger measures are needed to address it' (Long et al 2001:9). Similar research undertaken in the East Midlands of England indicated that racism was a relatively commonplace feature of the amateur game and that 'racist remarks are sometimes aimed at ethnic minority players by opposition players and spectators' (Bradbury 2002). More recently, research studies in the UK, Germany and the Netherlands have all alluded to the continued expressions of racialised abuse, harassment and inter ethnic tensions during competitive matches involving minority football clubs (Halm 2005, Van Sterkenburg et al 2005, Burdsey 2006, 2009, Kassimeris 2009b, and Bradbury 2010). Further, research undertaken on behalf of the European Union Federal Rights Agency found that incidents of racialised abuse are not restricted to adult football venues. The study uncovered empirical and anecdotal evidence from a range of EU member states which suggested that abuse of this kind emanated from a broad spectrum of generational cohorts including coaches, parents and spectators and often targeted children and young players from a range of minority backgrounds (EU/FRA 2010).

Perhaps the most common forms of overt racialised abuse reported in amateur football in the UK and Europe are those which utilise a series racial epithets designed to describe and demean black players. Racialised abuse of this kind shares distinct parallels with that which 
has been more commonly apparent amongst spectator formations in professional football and which has marked out players of African and African Caribbean heritage as 'subhuman' and 'ape-like'. However, there is also a growing body of evidence which has identified overt forms of abuse targeting amateur players on the basis of their cultural, religious or national background. For example, research studies have indicated that minority players from Turkish backgrounds in Austria, Belgium and Finland, Hungarians in Romania and Slovakia, Roma in Hungary and Bulgaria and Albanians in Greece, have all experienced overt forms of abuse which has drawn on ethno-nationalist, islamophobic, anti-semitic or anti-gypsy sentiment (Van Sterkenburg et al 2005, Kassimeris 2007, EU/FRA 2010). These studies also highlight the pejorative usage of descriptive markers of cultural and religious identity such as 'dirty Turk', 'shit Moroccan', 'fucking Jew', 'Gypsy cunt' and 'backward Muslim immigrant'.

Whilst overt racialised abuse of this kind is premised on a series of biological and (imagined) cultural referents, research studies have identified the increasing practice of much more subtle, nuanced and codified forms of racisms in the amateur game. For example, research in the UK has identified the conscious utilisation of deeply racialised coded insults which mark out black players as a kind of dangerous, criminal, animalistic, 'other' (Bradbury 2010). Similarly, the work of Burdsey $(2004,2007)$ is especially instructive in illustrating the multilayered processes of negative stereotyping and cultural 'othering' of South Asian, especially, Muslim heritage, amateur players in the UK. Research in Germany and the Netherlands has similarly identified culturally codified abuse targeting Turkish and Moroccan players as 'bag snatchers' and 'thieves' and has cited examples of opposition players and spectators imitating bleating goats and sheep (Van Sterkenburg 2005, Kassimeris 2009b). Similarly, players at predominantly Jewish teams in Austria, Germany, Belgium, Denmark, Austria and Hungary have all reportedly been subject to coded anti-semitism including comments regarding perceived physical and cultural traits and hissing sounds in reference to the gas chambers (EU/FRA 2010, Bradbury et al 2011).

Whilst incidences of racialised abuse in amateur football have often occurred as an immediate effect of 'heat of the moment' verbal and physical exchanges between players from different ethnic, cultural or religious backgrounds, they have also been utilised by opposition spectators and players as part of a framework of intimidating and hostile 
behaviours designed to 'wind-up' and 'unsettle' opponents (Muller et al 2007). These more instrumental expressions of racialised abuse are viewed - and often explained away - in dominant narratives as inherently non-ideological or as one element in a wider array of physical feature abuse which is considered to be 'part and parcel' of the game. These latter perspectives allude to a more broadly held set of norms and values within the heavily masculinised amateur (and professional) football arena which premise the acceptability of 'testing' opponents through 'trash talking' and 'banter' (Back et al 2001). However, these common sense accounts largely extricate expressions of racialised abuse from the deeply racialised structural, cultural and national contexts in which they take place and underplay the contextual intentionality and purpose of racist expression. Whilst it is of course the case that the perception of racism on the part of those who witness or experience it is not a necessary or sufficient condition of its existence, it is important to locate the interpretation of its meaning within the contextual layers and local settings in which these racialised actions are performed and acted out (Long and McNamee, 2004). In this respect, the use of racially coded signifiers can be understood as a distinctly situated and consciously strategic response by majority population players designed to reify cultural difference and encourage racialised antagonisms in a more consciously 'disguised' form. From this perspective, the continued expression of overt and culturally coded racialised abuse can be understood as offering symbolic opposition to notions of multi-culturalism as embodied within the demographic make up of teams with significant numbers of minority players. More specifically, such behaviours can also be read as designed (and understood) to mark out some contingent parameters of belonging and cultural inclusion within the sphere of amateur football and within local (and national) societal relations more broadly.

\section{Institutional racism and discrimination in amateur football}

There has thus far been little emphasis amongst academic and policy makers on examining the processes and outcomes of institutional racism and discrimination in amateur football. Broadly speaking, where attention has been paid to this area of study it has tended to focus on two key areas. Firstly, those more formal processes of racially inflected institutional closure emanating from the conjunctive relationship between national political models of citizenship and organisational practices and provision enacted by national governing bodies 
of football. Secondly, on those less formal relatively hidden forms of racialised exclusion embedded within the everyday operations of national and regional football federations and at amateur football clubs at the local level. With reference to more formal processes of institutional closure, the recent work of the Council of Europe: European Commission against Racism and Intolerance (ECRI) and the EU/FRA report on the exclusion of migrants and minorities in sport is particularly instructive. For example, the ECRI report on combating racism and racial discrimination in the field of sport refers in its general policy recommendation No. 12 to the existence of 'legal and administrative barriers to the participation of non citizens in local and national sports competitions in some countries' (2008:7). The report continues that as a result of these barriers both professional and amateur sports clubs have often been reluctant to admit persons who do not possess the citizenship of the country concerned. This is especially the case in a number of EU countries where national citizenship laws work in tandem with sports governing body's regulations to have a restricting effect on the participation of new migrants and generationally 'settled' minorities in sports, including amateur football. For example, the EU/FRA report has indicated that in one-third of EU member states fewer than between one and five citizens of other EU countries or third country nationals are allowed to participate in amateur football teams per game. This is the case in Austria, Malta, Spain, Greece, Germany, Portugal, Slovakia, Italy and Denmark. In these latter two countries, young first and second generation migrants cannot legally become national citizens before the age of 18 years old and football federations operate a series of quotas for national citizens in youth football. This has meant that for young new migrants and second generation minority children and young people born in these countries to parents from different countries of origin, opportunities to play organised football remain especially limited. At the recent Sport Inclusion Network and Football Against Racism in Europe conferences held in Vienna and Rome respectively in 2012, a number of academics, activists, and minority representatives argued forcefully that such practices were inherently discriminatory and were perceived to be in breach of the European Charter for Fundamental Rights which was ratified by the Lisbon Treaty in 2007 (EP/EC/EC 2007).

In addition to these deeply racialised formal legislative processes of exclusion, a number of research studies have illustrated the ways in which racially inflected patterns of institutional 
closure have been subtly enacted by pre-existing amateur clubs. The ethnographic studies of Burdsey $(2006,2009)$, Bradbury $(2010,2011)$ and Campbell $(2011)$ in examining the sociohistorical development of minority clubs in the UK locate the experiences of first and second generation minority players within the broader political context of England in the 1960s, 1970s and 1980s. These authors argue that in many major industrial areas in England during this period, rapidly changing local racial demography's engendered significant expression of resentment and hostility on the part of indigenous White communities towards newly arrived and recently settled minority communities. They continue that the expression of these wider societal racisms and embedded oppositions to racial integration were especially evident within the culture and practice of amateur football, where club affiliation was (and, arguably, still is) deeply rooted within heavily masculine and homogenously White neighbourhood and kinship networks. Further, these socially constructed patterns of organisation were felt to have contributed significantly to shaping the initial parameters and focus of inclusion and exclusion of young minority males in the amateur game and acted as an accelerant towards the formation of clubs from within minority kinship, community and religious networks. Other research studies have identified some comparable findings on this score with respect to the exclusion of marginalised Roma populations from mainstream amateur clubs in Central and Eastern Europe and the lack of throughput of minority players from recreational 'street football' to more structured participation in organised amateur football settings in Denmark and the Netherlands (Halm 2005, Agergaard and Sorenson 2009, Bradbury et al 2011).

A number of research studies in the UK and Europe have also alluded to the historically problematic relationship between minority football clubs and regional and national football federations in the UK and Europe. In particular, these studies reference accounts of unfair treatment and unequal disciplinary procedures enacted against minority clubs and the apparent reluctance of football federations to acknowledge and then deal swiftly, effectively and transparently with incidents of racialised abuse. For example, the EU/FRA report has cited examples of discriminatory treatment in the allocation of training and match-day facilities for minority participants in Austria, Germany and Finland and alludes to the strong cultural oppositions to the greater integration of Portuguese heritage minority teams into the national competition structures of the Luxembourg football federation (EU/FRA 2010). 
The work of Andersson in Sweden has drawn attention to the accounts of players at Stockholm based minority clubs which allude to unfair treatment by referees and the greater likelihood that minority players would be booked or sent off during games for committing similar offences to indigenous Swedish players who remained unpunished (Andersson 2009). Similarly, studies in the UK have identified the reluctance of referees to acknowledge incidents of racialised abuse and afford appropriate protection from abuse to minority players in this respect (Williams 1994, Burdsey 2006, 2009). Bradbury (2011) has also noted a marked discontentment amongst minority clubs England with respect to the often lengthy, unwieldy, and 'behind closed doors' approach of disciplinary procedures enacted by regional federations in the amateur game.

To some extent, the lack of action taken against racialised abuse in amateur football is informed by the residual embeddedness of some deeply held cultural stereotypes which have problematised minority players as 'troublesome' and 'hot-headed. For example, research undertaken by Long et al (2001) and Bradbury (2002) found that processes of negative stereotyping were relatively commonplace within the amateur football fraternity in the UK, with particular regard to black and South Asian players. Similarly, Turkish and Moroccan players in the Netherlands and Germany, Somali players in Denmark, and players from the Balkans in Central and Eastern Europe have been comparably marked out in amateur football as having a 'bad attitude' and being 'difficult' (Agergaard and Sorenson 2009, EU/FRA 2010, Bradbury et al 2011). Further, Andersson has noted some historical consistencies in media coverage of amateur football in Stockholm which has labelled Southern European minorities from Greece and Croatia as 'temperamental' and 'violent', in contrast to the perceived 'calm-ness' and 'respectful' manner of indigenous Swedish players (Andersson 2009). This problematisation of minority players has also been extended to those who have actively spoken out against racialised abuse in the amateur game and who have invariably been accused of 'complaining' and 'being confrontational' and as 'playing the race card'. This practice has allowed football federations to deny the widespread existence and veracity of racism in the amateur game and has limited the parameters in which overt and more subtle manifestations of racialised abuse can be challenged and redressed. To this end, the work of Lusted $(2009,2011)$ is particularly instructive in identifying the traditional modus operandi of regional football governance in the UK and the distinctly conservative and 
colonialist ideologies of largely older, white, males who occupy powerful positions within this voluntary and relatively autonomous infrastructure. Lusted argues that the deeply embedded hegemonic whiteness and racialised power-base within amateur football governance enables a series of culturally defensive and protectionist rather than reformist philosophies and practices to be sustained over time. Further, the limited accountability of such bodies to the national ownership of the game confers significant authority on senior officials to act as key gate-keepers to the process of enabling or denying best racial equality practice at the local level. From this perspective, the non-recognition and lack of commitment to act against racism in amateur football and the problematisation of minority behaviours can be read as collective failure of football federations to provide an equitable service to its broad and culturally diverse constituency of amateur players. This analysis chimes strongly with the broadly accepted notion of institutional racism outlined in the McPherson report (1999) which suggests that discrimination of this kind can be 'detected in processes, attitudes and behaviour which amount to discrimination through unwitting prejudice, ignorance, thoughtlessness and racist stereotyping which disadvantage minority groups'.

\section{Resisting racisms in amateur football: the case of minority clubs}

Whilst the practice and experiences of myriad forms of overt, cultural and institutional racisms has been a relatively commonplace feature of amateur football in the UK and Europe, the amateur game has also been a site in which racisms of this kind have been negotiated and contested across a range of local, regional and national contexts. For example, research studies charting the socio-historical development of minority participation in organised amateur football in the UK have explicitly linked the formation of minority clubs with experiences of racial closure at pre-existing (white) amateur clubs (Bradbury 2010, 2011, Burdsey 2006, 2009, Campbell 2011). These authors have argued that since this time these minority clubs have provided a conscious physical safeguard against the ongoing realities of overt racist expression and more subtle, nuanced and codified forms of cultural racisms and have provided safe and supportive leisure spaces for players from minority backgrounds. Further, a number of authors have referenced the importance of minority clubs in terms of their assumed position as a highly visible cultural resource and 
symbolic marker for the construction and expression of specific ethnic and religious identities (Westwood 1990, 1991, Williams 1994, Carrington, 1998, 1999 and Burdsey 2006, $2007,2009)$. In particular, these authors suggest that minority football (and cricket) clubs have acted as sites of cultural resistance to wider societal racism and perceived community injustice through their involvement in victories against perceived historical oppressors and the celebration of the minority sporting achievement. From these perspectives, minority clubs are understood to represent discursively constructed and distinctly racialised symbolic spaces within which participation has come to constitute a form of local community politics and community empowerment.

Research undertaken by Bradbury $(20010,2011)$ and Burdsey $(2006,2009)$ has also referenced the identifiable (and identifiably) different social, cultural and religious attachments of minority clubs in the UK. These authors suggest that the historically embedded cultural identities of clubs of this kind has helped sustain the organizational commitment of older minority participants as club coaches and administrators and has continued to engender a strong cultural appeal to new youth cohorts. This is especially the case at South Asian clubs which have strong developmental connections to specific religious places of worship such as Sikh temples and which enable opportunities for familial, cultural and religious continuities and socialisation. Further, Bradbury has argued that whilst key organizers at these South Asian clubs have made conscious attempts to avoid the kinds of racial closure which had previously impacted on their own personal experience of the game, it is likely that clubs of this kind probably have relatively limited wider appeal to players from other religious or more secular backgrounds. Also, deeply embedded racist sentiment and residual cultural stereotypes has probably gravitated against greater sporting integration in this respect and maintained the relative demographic homogeneity of these clubs. In contrast, other minority football clubs with less explicit cultural and religious affiliations have been a little more successful in diversifying the make-up of teams to include young players from a range of ethnic backgrounds with a strong connectedness to the everyday lived experiences of some urban multicultural settings. This is especially where there is a strong and highly politicized ethos regarding the social function of clubs as facilitators of multi-ethnic service provision for youth communities experiencing disproportionate levels of social, economic and cultural marginalization. Regardless of their 
cultural identities and make-up, minority clubs in the UK have provided valuable participation opportunities in organised football for a range of marginalised communities for whom access to local organized football has been institutionally and historically limited. Further, the conscious facilitation of inter-cultural leisure spaces at clubs has enabled young people to actively extend social connections with players from a diverse range of ethnic backgrounds. In this respect, some minority clubs have come to occupy a site in which meaningful and equitable racial integration is being positively enacted, at least within some distinctly generational, classed and highly localised settings. To this end, minority clubs can be understood to offer a practical and ideological 'third space' (Bhabha 1990a, 1990b) in which the potential for new diverse inclusions and cross cultural interaction might contribute to the production new culturally hybrid identities premised on the celebration of diversity and the shared social, cultural and sporting habitus of youthful populations drawn from specific multi-ethnic locales.

\section{Concluding comments: the limits of resistance and the centrality of hegemonic whiteness}

Despite the realised efforts of minority clubs to enable collective physical and symbolic resistance to racisms, promote community empowerment and racial integration, and facilitate the production of new multi-ethnic leisure spaces, their capacity to challenge and disrupt some deeply racialised hegemonic power relations embedded within the core structures of amateur football and beyond remains limited. In the first instance, the potential of minority clubs to engender increased participation opportunities and generate positive wider social outcomes for participants cannot be divorced from the wider structural dynamic and racial politics of the societies in which they are situated. In many more ethnically and culturally polarised nation states across Europe where attitudes to 'race' have been much less malleable over time and where their exists a deeply embedded cultural resistance to the inclusion of minorities in local social relations, the likelihood of success in combating racism and enabling more equitable participation in amateur football is markedly lessened. This is arguably especially the case in countries in Central and Eastern Europe which exhibit rigid models of national identity and citizenship and where there is a marked defensiveness and general de-prioritisation of policy interventions designed to address minority discrimination. However, it is probably also the case in many Western European 
countries where in the post $9 / 11$ period of modern history there is a growing sense of 'democratic impatience' at the perceived lack of integration of Muslim communities and a general shift in political thinking away from multiculturalism towards the rhetoric and policy of integration and assimilation (Parekh 2006, Kymlicka 2010, Vertovec and Wessendorf 2010).

In the second instance, there is little evidence to suggest that increased levels of minority participation in the game as players has enabled greater access to and adaptation of the presently inadequate and inequitable structures of governance at regional and national football federations. For example, research undertaken by Bradbury et al (2011) indicates that less than $1 \%$ of officials within the senior administrative and governance tiers of national football federations in the UK and Europe were drawn from 'visible' minority populations, and that minority representation within regional structures remained marginal. Within the hierarchical pyramid structures of national and regional football federation's initial access to executive decision making committees are often premised on the sponsored mobility, patronage and personal recommendation of more senior figures within these governing bodies. These 'promotions' are commonly perceived as a reward for individuals who have exhibited long standing paid and/or voluntary services to football in their regions or at a national level. Given the historically inscribed power relations and limited existing demographic of older, white, males, within football governance infrastructures, it is hardly unsurprising that minority populations continue to be marginalised from the benefits and profits of these hegemonic white networks of mutual acquaintance. Whilst the relative absence of minorities from these governance infrastructures is underpinned by processes of unconscious and indirect forms of institutional discrimination, a number of authors have suggested some deeply embedded 'cultures of resistance' to more equitable change amongst key stakeholders within the governance of the game (Bradbury et al 2011, Hylton 2009, 2010, Long 2000, 2007, Long et al 2002, 2005, 2011, Lusted 2009, 2011). This resistance to change is to some extent reflective of the dominant political paradigms in certain nation states, in which relatively closed models of national identity and citizenship underpin limited policy approaches to dealing with minorities premised on assimilation or non intervention. Resistance might also indicate a more general lack of 'problem awareness' or non-acknowledgement of the concept and practices of institutional discrimination and 
represent a reactionary response to perceived personal criticisms on this score. However, it is of course also likely that in some cases this resistance is more reflective of a general reluctance to surrender accrued rewards and decision making powers at the personal level. Nonetheless, in each case these practices of resistance are underscored by a series of deeply racialised hegemonic power relations embedded within the core structures and decision making bodies of football governance. To this end, we might argue that the centrality and invisibility of whiteness which enables the 'reproduction of dominance rather than subordination, normativity rather than marginality, and privilege rather than disadvantage' (Frankenburg 1993: 237) has maintained the status quo of social relations within the organisational tiers of amateur football. Further, the intrinsic relationship between whiteness and the processes and practices of institutional discrimination has limited the scope of minority engagement with the popular physical and cultural leisure space of amateur football and offered few opportunities for recourse against racisms in all its myriad forms. In doing so, this has rendered the experiences of minorities as marginal to and less valued than that of majority populations and has consequently hindered a stronger sense of cultural belonging in the sport amongst minorities in the UK and Europe. Future efforts to ensure the equal treatment of minorities in amateur football and in other sports can arguably only be realised through the dismantling of those deeply racialised hegemonic power relations embedded within the organisational make-up of sports bodies which position minorities as fit for 'doing' but not 'organising' sports and leisure practices. This will require a significant perceptual shift towards viewing cultural diversity as a positive individual and organisational resource rather than as a problem to be dealt with. However, it is likely that the adoption of this more inclusive approach will contribute to the added value of organisations and increase their capacities to connect with and provide a more equitable service to the increasingly diverse populations of the societies in which they are situated. In this sense, in amateur football and in sport and leisure practice more broadly, it's still all to play for.

Word count: 6.076

\section{References}


Agergaard, S., and Sorenson, J.K. (2009) 'The dream of social mobility: ethnic minority players in Danish football clubs', Soccer and Society. Vol 10 (6) 766-780

Ahmed, A. (2011) British Muslim female experiences in football: Islam, identity and the hijab in Burdsey, D. (ed.) Race, Ethnicity and Football: Persisting Debates and Emergent Issues Abingdon: Routledge.

Anderson, T. (2009) 'Immigrant teams in Sweden and the case of Assyriska FF', Soccer and Society. Vol 10. 398-417

Anthias, F, and and Yuval Davies, N. (1993) Racialised boundaries: London. Routledge

Bhabha, H. (1990a) 'The third space - interview with Homi Bhabha' in Rutherford, J (ed) Identity, Community, Culture, Difference London, Lawrence and Wishart.

Bhabha, H. (1990b) 'Interrogating Identity: The post-colonial perogative' in Goldberg, D. Anatomy of Racism. University of Minnesota.

Back, L., Crabbe, T. and Solomos, J. (1998) Racism in Football: Patterns of Continuity and Change in A.Brown ed. Fanatics!: Power, identity and fandom in football. Routledge

Back, L,. Crabbe, T., Solomos, J. (2001) The Changing Face of Football: Racism, identity and multiculture in the English game Oxford: Berg

Bains J. with Patel R. (1996) Asians can't play football. Birmingham: Asian SocialDevelopment Agency.

Bains, J. (2005) Asians can play football: Another wasted decade. University of Leicester

Bradbury, S. (2002) A survey of local football clubs affiliated to the Leicestershire and Rutland County FA: Issues of racism, ethnicity and player and spectator behaviour in local football. SNCCFR

Bradbury, S. (2010) 'From racial exclusions to new inclusions: Black and minority ethnic participation in football clubs in the East Midlands of England', International Review of the Sociology of Sport

Bradbury, S. (2011) 'Racisms, resistance and new youth inclusions: the socio-historical development and shifting focus of black, Asian and minority ethnic football clubs in Leicester in Burdsey, D. (ed.) Race, Ethnicity and Football: Persisting Debates and Emergent Issues Abingdon: Routledge.

Bradbury, S., Amara, M., Garcia, B., Bairner, A. (2011) Representation and structural discrimination in football in Europe: The case of minorities and women. Loughborough University

Bloch, A., \& Levy, C. (Eds.). (1999). Refugees, citizenship, and social policy in Europe.London: Macmillan

Burdsey, D. (2004) 'Obstacle race?: Race, racism and the recruitment of Asian professional footballers' Patterns of Prejudice, Vol 38, No 3, pp 279-30

Burdsey, D. (2006) 'No ball games allowed? A socio-historical examination of the development and social significance of British Asian football clubs', Journal of Ethnic and Migration Studies Vol $32 \mathrm{pp}$ 477-496 
Burdsey, D. (2007) British Asians and Football: Culture, identity and exclusion. London. Routledge

Bursdey, D. (2009) 'Forgotten Fields? Centralising the experiences of minority ethnic men's football clubs in England', Soccer and Society Vol 10 (6) 704-721

Campbell, P. (2011) What is Rangers resisting now? 'Race', resistance and shifting notions of blackness in local football in Leicester in Burdsey, D. (ed.) Race, Ethnicity and Football: Persisting Debates and Emergent Issues Abingdon: Routledge.

Carrington, B. (1998) Sport, masculinity and black cultural resistance. Journal of Sport and Social Issues (22) 3 275-298

Carrington, B. (1999) Cricket, culture and identity: an ethnographic analysis of the significance of sport within black communities in Roseneil, S. and Seymour, J. (eds) Practising identities: Power and resistance. London. Macmillan

Carrington, B. (2010) Race, Sport and Politics: The sporting black diaspora, Sage, London/Thousand Oaks.

Cashmore, E. (1982), Black Sportsmen. London: Routledge

Commission for Racial Equality (2004) Racial Equality in Football. CRE

Council of Europe: European Commission against Racism and Intolerance (2008): ECRI General Policy Recommendation No.12 on Combating racism and racial discrimination in the field of sport adopted on 19 December 2008 CRI(2009)5 (19 December 2008).

European Parliament, Council and Commission (2007) Charter of Fundamental Rights of the European Union. 2007/C303/01.

European Union for Fundamental Rights (2010) Racism, ethnic discrimination and exclusion of migrants and minorities in sport: A comparative overview of the situation in the European Union.

FARE (2010) Ukranian right wing group marches against 'foreign' footballers http://www.farenet.org/default.asp?intPagelD=7\&intArticlelD=2240/sport1/hi/football/europe/909 7434.stm

Football Task Force (1998) Eliminating Racism from Football: A report by the football task force submitted to the Minister for Sport. London: The Football Trust.

Frankenburg, R. (1999) Displacing Whiteness. Durham and London. Duke University Press

Garland, J. and Rowe, M. (2001) Racism and Anti-Racism in Football, Palgrave

Halm, D. (2005) Turkish immigrants in German Amateur football in Tomlinson, A., and Young, C., German Football: History, Culture and Society. London and New York Routledge. pp 73-92

Hylton, K. (2009) Race and Sport: Critical race theory. Routledge. London and New York

Hylton, K (2010) 'How a turn to critical race theory can contribute to our understanding of "race", racism and anti-racism in sport', International Review for the Sociology of Sport, 45, 3: 335-54. 
Independent Football Commission (2003) Annual Report IFC

Kassimeris, C. (2007) European Football in Black and White: Tackling Racism in Football Lanham, MD: Lexington Books

Kassimeris, C., (2009a) Deutschland Uber Alless: discrimination in German football. Soccer and Society. Vol 10 (6) 754-765

Kassimeris, C. (2009b) Football and Prejudice in Belgium and the Netherlands. Sport and Society Vol 12 (10) 1327-1335

Kay, T. (2006) ‘Daughters of Islam: Family influences on Muslim young women's participation in sport', International review for the Sociology of Sport 41 (3/4), 357

King, C. (2004a) Offside Racism: playing the white man, (Oxford: Berg).

King, C. (2004b) 'Race' and Cultural Identity: playing the race game inside football', Leisure Studies, 23, 19-30.

Kymlicka, W. (2010) The rise and fall of multiculturalism?: new debates on accommodation and inclusion in diverse societies' in Vertovec, S. \& Wessendorf, S.(eds.) The Multiculturalism Backlash: European Discourses, Policies and Practices. Abingdon: Routledge.

Krouwel, A., Boonstra, N., Duyvendak, W., Veldboer, L. (2006) 'A Good Sport? Research into the Capacity of Recreational Sport to Integrate Dutch Minorities', International Review of Socioklogy of Sport. Vol 41 (2) 165-180

Llopis-Giog, R (2009) Racism and Xenophobia in Spanish Football: Facts, Reactions and Policies. Physical Culture and Sports Studies 47 (1) 35-43

Long, J. and Spracklen, K. (eds). Sport and Challenges to Racism. Palgrave Macmillan

Long, J. (2000) 'No racism here? A preliminary examination of sporting innocence' Managing Leisure Vol 5, pp121-133

Long, J., Hylton, K., Welch, M., Dart, J. (2001) 'Part of the Game: A report prepared for Kick It Out for the Centre of Leisure and Sport Research at Leeds Metropolitan University. Kick It Out.

Long, J. \& Hylton, K. (2002) Shades of White: An Examination of Whiteness in Sport. Leisure Studies, 21, 87-103.

Long, J. and McNamee, M. (2004) On the moral economy of racism and racist rationalisations in sport. International Review of the Sociology of Sport 39/4 405-438

Long, J., Robinson, P., Spracklen, K. (2005) Promoting Racial Equality Within Sports Organisations in Journal of Sport and Social issues. Vol 29 (1) 41-59

Long, J., Hylton, K., Spracklen, K., Ratna, A., Bailey, S. (2009) 'Systematic review of the literature on Black and Minority Ethnic communities in sport and physical recreation' Carnegie Research Institute, Leeds Metropolitan University 
Lusted, J. (2009) 'Playing games with 'race': understanding resistance to 'race' equality initiatives in English local football governance' Soccer and Society, Vol 10, No 6, 722-739

Lusted, J. (2011) Negative equity? Amateurist responses to race equality initiatives in English grassroots football in Burdsey, D. (ed.) Race, Ethnicity and Football: Persisting Debates and Emergent Issues Abingdon: Routledge.

Macpherson, W. (1999) 'The Stephen Lawrence Inquiry: report of an Inquiry made by Sir William Macpherson of Cluny', London: Home Office, Cm 4262-I.

Müller, F., van Zoonen, L. \& de Roode, L. (2007) 'Accidental racists: experiences and contradictions of racism in local Amsterdam soccer fan culture', Soccer and Society, 8, 2/3: 335-50.

Nash, R. (2000) 'Contestation in modern English professional Football', International Review of the Sociology of Sport Vol 35, No 4, pp 456-486

Parekh, B. (2006) Rethinking Multiculturalism: Cultural Diversity and Political Theory (Second Edition) Basingstoke: Palgrave.

Pillai, R., Kyambi, S., Nowacka, K., and Sriskandarajah, D. (2006) The Reception and Integration of New Migrant Communities London. Institute of Public Policy Research

Ratna, A. (2007) A Fair Game? British Asian females experience of racism in womens football in Magee, J., Cauldwell, J., Listone, K. and Scraton, S. (eds) Women, Football and Europe: Histories, Equity and Experiences. Oxford. Meyer and Meyer Sport Ltd.

Robson, G. (2000) No One Likes Us, we don't care: The myth and reality of Millwall fandom, Oxford. Berg.

Roversi. A. (1994) 'The birth of the Ultras: the rise of football hooliganism in Italy' in Williams, J. and Giullianotti, R. (eds) Games Without Frontiers Aldershot: Aldgate

Rowe, N., \& Champion, R. (2000). Sports Participation and Ethnicity in England: National Survey 1999/2000 (No. SE/1073 WC1H OQP): Sport England.

Scraton, S., Cauldwell, J., and Holland, S. (2005) 'Bend it Like Patel: Centring 'Race', Ethnicity and Gender in Feminist Analysis of Women's Football in England' in International Review for the Sociology of Sport. Vol 40 (1): 71-88

Spaaij, R., Vinas, C. (2005) 'Passions, Politics and Violence: A Socio-historical Analysis of Spanish Ultras', Soccer and Society. Vol 6 (1) pp: 79-96

Van Sterkenburg, J., Janssens, J., Rijen, B (Eds) (2005) Football and Racism: An inventory of the problems and solutions in eight West European countries in the framework of the Stand Up Speak Up campaign. Brussels, Muller Institute.

Vertovec, S. \& Wessendorf, S. (2010) 'Introduction: assessing the backlash against multiculturalism in Europe' in in Vertovec, S. \& Wessendorf, S.(eds.) The Multiculturalism Backlash: European Discourses, Policies and Practices. Abingdon: Routledge. 
Westwood, S. (1990), "Racism, black masculinity and the politics of space" in Hearn, J. and Morgan, D. (eds), (1990), Men, Masculinities and Social Theory, Unwin and Hyman, pp. 55-71

Westwood, S. (1991) 'Red Star over Leicester: Racism, the politics of identity and black youth in Britain' in Werbner, p and Anwar, M. (eds) (1991) Black and Ethnic Leadership in Britain. London. Routledge.

Williams, J. (1984) On the Football Front SNCCFR. University of Leicester

Williams, J. (1992) Lick My Boots: Racism in English football. SNCCFR, University of Leicester

Williams, J. (1994) 'Rangers is a black club: Race, identity and local football in England' in Guilianotti, R and Williams, J. (eds) Game Without Frontiers: Football identity and modernity. Aldershot: Arena. 